Pediatr Neurosurg 2010;46:415-416

DOI: $10.1159 / 000325152$

\section{Commentary on 'Quality of Life and Myelomeningocele: An Ethical and Evidence-Based Analysis of the Groningen Protocol' by Sean Barry, Pediatr Neurosurg 2010;46:409-414}

Patricia A. Aronin, Timothy M. George

Pediatric Neurosurgery, Dell Children's Medical Center, Austin, Tex., USA

Since its publication in the New England Journal of Medicine [1] and in Pediatrics [2] in 2005, numerous articles have been published in ethics and neonatology journals [3-10] debating the appropriateness of the Groningen Protocol (GP) in deciding to end the life of a neonate with spina bifida. The protocol was proposed as a standard of practice for the management of severely impaired newborns. Strikingly little has appeared in the neurosurgery literature [11] despite the vital role played by pediatric neurosurgeons in the care of these infants. For this, Sean Barry [12] is to be commended, as it is important to raise our level of awareness of protocols such as this which have such a profound effect on the management of these babies.

However, this article also demonstrates the difficulty of trying to subject quality- and value-of-life decisions to the rigors of the scientific method. This is not a scientific analysis, as there is no quantification of the measures that formed the basis of the GP or the cases that were reported in that original publication - details of the individual infants are lacking. Rather, Barry gives his reasons for disagreeing with the premises of the GP, and while we agree with him, that does not constitute a scientific proof of the inadequacies of its design. The GP was certainly not designed on the basis of any sort of clinical trials. Nonetheless, Barry does present evidence approaching level III to support his condemnation of the protocol.

Evidence-based medicine is a tool of considerable value for medicine and neurosurgery that provides a secure base for clinical practice and practice improvement, but is not without inherent drawbacks, weaknesses and limitations [13]. While Barry should be credited for his attempt, this paper demonstrates how difficult it is to address ethics scientifically. Not all medical decision-making is scientific, but it should be based upon the best information available. The GP was based on observational studies with a design bias that the designers knew the outcome of the infants was worse than death. Barry relies on other descriptive and observational studies to point out the fallacy of that conclusion. If left unrefuted, the GP encourages a practice that condones the elimination of viable infants just because they are born with significant disabilities. Berry's paper reviews the many shortcomings of the premises that form the basis of the GP. Advances in neurosurgical care of infants with congenital anomalies, enhanced by the development of the subspecialty of pediatric neurosurgery, have resulted in improved survival and function of infants with myelomeningocele. In his paper, Barry reviews the many arguments against the GP $[3-7,11]$, including the imprecise terminology and vagueness of the protocol. It is this very vagueness of the original protocol that makes an evidence-based refutal impossible. We do not know exactly what constituted a 'severely impaired infant', and Dr. Barry is willing to accept that they were all 'severely affected'. Nor does the protocol elaborate on what were the 'standard medical means' for terminating their lives.

While the treating physicians in the GP may feel that the projected life of these infants is intolerable, that might not be the opinion of the affected individual. As has been reported by Barf and Post [14], life satisfaction questionnaires from young adults with spina bifida suggest that spina bifida did not seem to be an important determinant of life satisfaction. The GP fails to explain how it was determined that the infants were experiencing 'hopeless and unbearable suffering. The GP also ignores the resolution adopted by the International Federation for Spina Bifida and Hydrocephalus adopted in September 2000: 'Adults with spina bifida and/or hydrocephalus underline that their quality of life is not and should not be given as - a reason for abortion.' They further maintain that no one is in a better position to make a judgment about his/her quality of life than the spina bifida patient him-/ herself [15].

The greatest merit of Barry's paper is in raising our awareness of the dangers of enacting the practice management guidelines of the GP. This is an excellent reminder to pediatric neurosurgeons of the need to be involved in such decision-making and to educate both parents and pediatric and neonatology colleagues of the real outcomes of the spina bifida population. It is also a reminder that despite our experience and training, no physician can perfectly predict the future [11], and decisions to terminate life should not be made based upon our own biases about quality of life of a disabled patient. Using such criteria is ethically unacceptable in making a decision to terminate the life of a neonate [10]. For the pediatric neurosurgeon, we must become vocal participants in this debate. We must become proactive in the establishment of evidence-based medicine guidelines and actively involved in outcomes research. The advances in basic research have also called for us to champion hope for the future of children with spina bifida. Future decisions about healthcare rationing and how to spend our healthcare dollars cause each of us to carefully consider these issues.

\section{KARGER}

Fax +41 613061234 E-Mail karger@karger.ch www.karger.com
(อ) 2011 S. Karger AG, Basel

1016-2291/10/0466-0415\$26.00/0 


\section{References}

$\checkmark 1$ Verhagen E, Sauer P: The Groningen Protocol - euthanasia in severely ill newborns. N Engl J Med 2005;352:959-962.

2 Verhagen AA, Sauer PJ: End of life decisions in newborns: an approach from the Netherlands. Pediatrics 2005;116:736-739.

$\checkmark 3$ Kon AA: Neonatal euthanasia is unsupportable: the Groningen protocol should be abandoned. Theor Med Bioeth 2007;28:453-463.

4 Jotkowitz A, Glick S: The Groningen protocol: another perspective. J Med Ethics 2006;32:157-158.

5 Gesundheit B, Steinberg A, Blazer S, Jotkowitz A: The Groningen Protocol - the Jewish perspective. Neonatology 2009;96:6-10.

6 Lindemann H, Verkerk M: Ending the life of a newborn: the Groningen Protocol. Hastings Cent Rep 2008;38:42-51.

7 Jotkowitz A, Glick S, Gesundheit B: A case against non-voluntary active euthanasia (the Groningen protocol). Am J Bioeth 2008;8:23-26.

$\checkmark 8$ Manninen BA: A case for justified non-voluntary active euthanasia: exploring the ethics of the Groningen Protocol. J Med Ethics 2006;32: 643-651.

-9 Kompanje EJ, de Jong TH, Arts WF, Rotteveel JJ: Questionable basis for 'hopeless and unbearable suffering' as the criterion for the active termination of life in newborns with spina bifida. Ned Tijdschr Geneeskd 2005;149:2067-2069.
10 Manninen BA: Regarding the Groningen Protocol (eLetter to the editor). J Med Ethics, Nov 23, 2006.

11 De Jong TH: Deliberate termination of life of newborns with spina bifida, a critical reappraisal. Childs Nerv Syst 2008;24:13-38.

12 Barry S: Quality of life and myelomeningocele: an ethical and evidencebased analysis of the Groningen Protocol. Pediatr Neurosurg 2010;46: 409-414.

13 Linskey ME: Evidence-Based Medicine for Neurosurgeons: Introduction and Methodology. Prog Neurol Surg. Basel, Karger, 2006, vol 19, pp 1-53.

14 Barf HA, Post MW: Life satisfaction of young adults with spina bifida. Dev Med Child Neurol 2007;49:458-463.

15 Resolution on Prenatal Diagnosis and the Right to be Different. International Federation for Spina Bifida and Hydrocephalus Annual General Meeting, Toulouse, Sept 2000.

Timothy M. George

Pediatric Neurosurgery

Dell Children's Medical Center

Austin, TX 78723 (USA)

E-Mail tmgeorge@seton.org 